\title{
Cell biology and medical education - a thematic issue dedicated to Adi Ellinger
}

\author{
Margit Pavelka
}

(C) Springer-Verlag GmbH Austria, ein Teil von Springer Nature 2018

This special themed issue of the Wiener Medizinische Wochenschrift addresses various different topics which have in common that they are all connected with Adi Ellinger in some way. Colleagues of Adi's, who worked with him either recently or many years ago, have been invited to contribute to this issue by submitting a manuscript on one of the topics on which they collaborated. The list of the articles mirrors Adi's different interests and his successful collaborations. It is one of the specific features of this issue that contributions of scientific work on burning cell biology questions are alongside topics that have a central role in the teaching and education of medical students. I am very happy and grateful that all those invited scientists, former or current colleagues, and co-workers of Adi's accepted the invitation to contribute to this issue.

Two articles are dedicated to medical education. Rudolf Mallinger contributes with a comprehensive text about the history and actual questions on University and Medicine ("Universität und Medizin"). Details of the reform processes relating to the development of a new curriculum for medical students (MCW) are described in the article by Richard März ("A scientific approach to the reform of a medical curriculum: a personal account of the Vienna experience"). The topics addressed in the other contributions provide actual insights into cellular life and death. Essential cell functions in healthy and diseased cells are highlighted, such as cholesterol metabolism in the article by Clemens Röhrl and Herbert Stangl ("Cholesterol metabolism-physiological regulation and pathophysiological de-regulation by the endo-

Em. O. Univ.-Prof. Dr. M. Pavelka (ه)

Center for Anatomy and Cell Biology, Medical University of

Vienna, Schwarzspanierstraße 17, 1090 Vienna, Austria

margit.pavelka@meduniwien.ac.at plasmic reticulum"), roles of NADPH oxidases in the article by Michael Breitenbach and colleagues ("The defense and signaling role of NADPH oxidases in eukaryotic cells"), and processes of cell death in the article by Wilfried Bursch ("A cell's agony of choice: how to cross the Styx?-From morphological to molecular approaches to disclose its decision"). Branko Velimirov and Carmen Ranftler report on horizontal gene transfer of prokaryotes in their article entitled "Commenting unexpected aspects in the dynamics of horizontal gene transfer of procaryotes: The impact of outer membrane vesicles." Novel technical approaches are a main focus of the articles by Stéphane Blouin and Klaus Klaushofer ("Confocal laser scanning microscopy - a powerful tool in bone research”) and Josef Neumüller ("Electron tomography-a tool for ultrastructural 3D visualization in cell biology and histology").

During the work on this issue, "old" contacts between Adi's working colleagues, including myself, were renewed and memories exchanged. We remembered the work together with Adi in the historical laboratories in Schwarzspanierstraße headed by Prof. Stockinger, the hours we spent sitting behind the electron microscope, the collaboration with colleagues in the different groups, the preparations for the meetings we attended and our conference trips together, as well as private activities. These times with Adi were fruitful and exciting. Everybody appreciated how he always acted competently and in a helpful manner. No less intense are the memories on our joint commitment in the processes linked to MCW implementation, as described in detail in the article by Richard März. Adi volunteered to be the first "block coordinator" and was intensely involved in all stages of the reform process.

My own collaboration with Adi Ellinger has lasted from the 1980s until today, and is characterized by our 


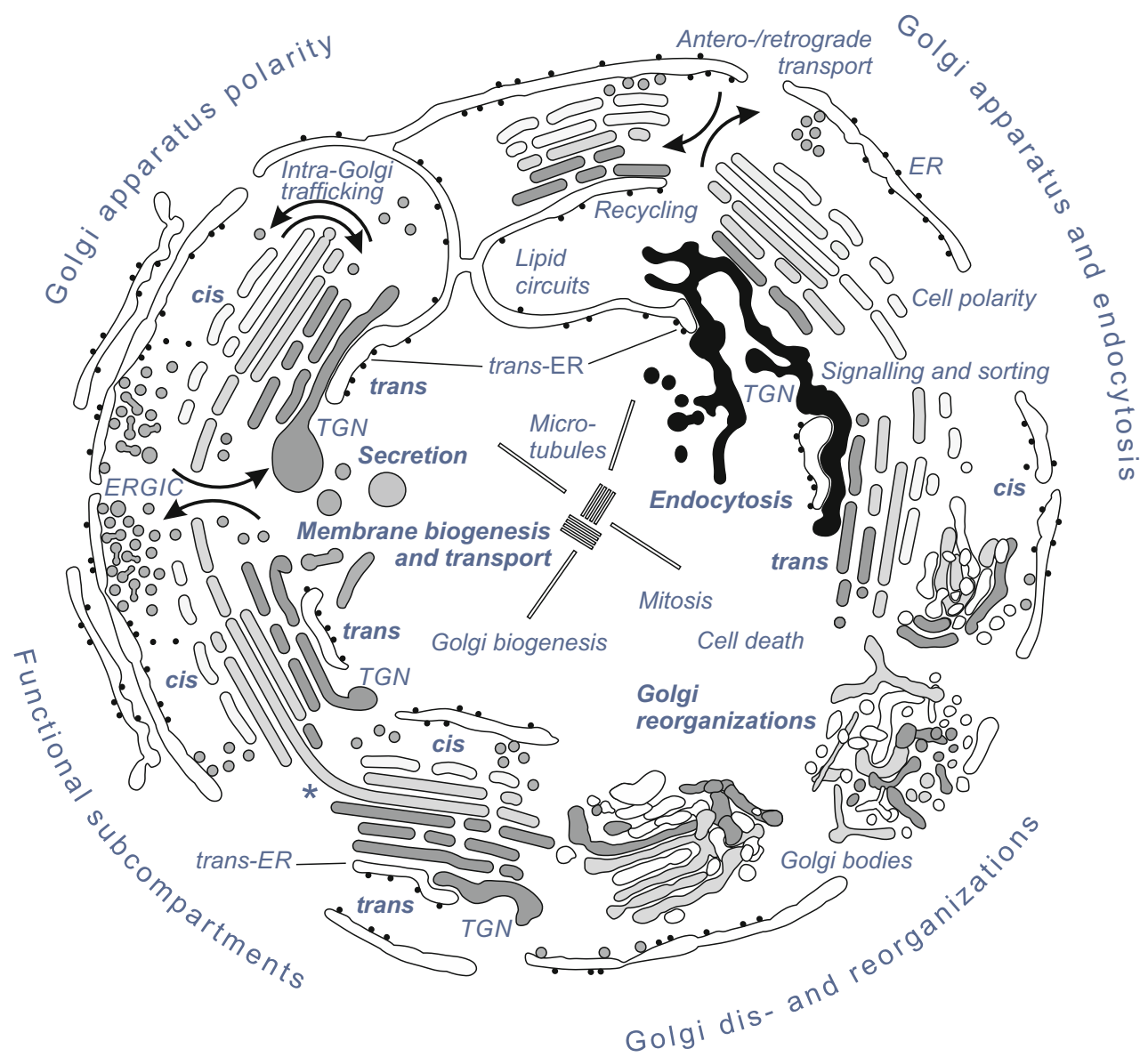

Fig. 1 Updated from Fig. 1 in Pavelka and Roth [1]. ER endoplasmic reticulum, TGN trans-Golgi network, ERGIC endoplasmic reticulum-Golgi-intermediate compartment

enthusiastic work on the structure and function of the Golgi apparatus. The Golgi apparatus is a unique organelle with a very complex and dynamic architecture that mirrors its multiple functions as a central crossroads in cellular traffic. The figure (Fig. 1) gives an impression of the complex structural composition of this organelle built up of stacks of cisternae, tubules, and multiple vesicles. The labels indicate the cis-trans polarities of the Golgi stacks and main cellular tasks in which the Golgi apparatus is involved, such as secretion and endocytosis, membrane biogenesis and recycling, signaling and sorting, mitosis and cell death. In the circle, the main topics of our joint research (Adi's and mine) into the Golgi apparatus over almost 40 years are summarized, focusing on Golgi apparatus polarities, the characterization of functional subcompartments, the role of the Golgi apparatus in endocytosis, and Golgi apparatus dis- and reorganizations.

No less enthusiastic was our (Adi's and mine) engagement in teaching and medical education. We were both coordinators of one of the thematic "blocks" by which the new curriculum was structured. Adi and I often had very different opinions and I remember emotional discussions lasting hours and hours, without yielding acceptable results. I will never forget those exciting times.

Adi, a heartfelt thank you for all your cooperation and friendship, and very best wishes for the future.

Acknowledgements I cordially thank all authors of this issue for their contributions and all reviewers who helped me to do my work as a guest editor. I thank Mr Thomas Nardelli for his help with the figure and I thank Julia Rotter, MA, from the Springer office in Vienna for all her help and advice and the excellent cooperation.

Conflict of interest M. Pavelka declares that she has no competing interests.

\section{References}

1. Pavelka M, Roth J. In focus in Bad Ischl: Golgi apparatus 2013. Histochem Cell Biol. 2013;140:233-4. 